\title{
A RELAÇÃO DE TRADUÇÃO ESPANHOL < > PORTUGUÊS: QUESTÕES DE (DES)SEMELHANÇAS
}
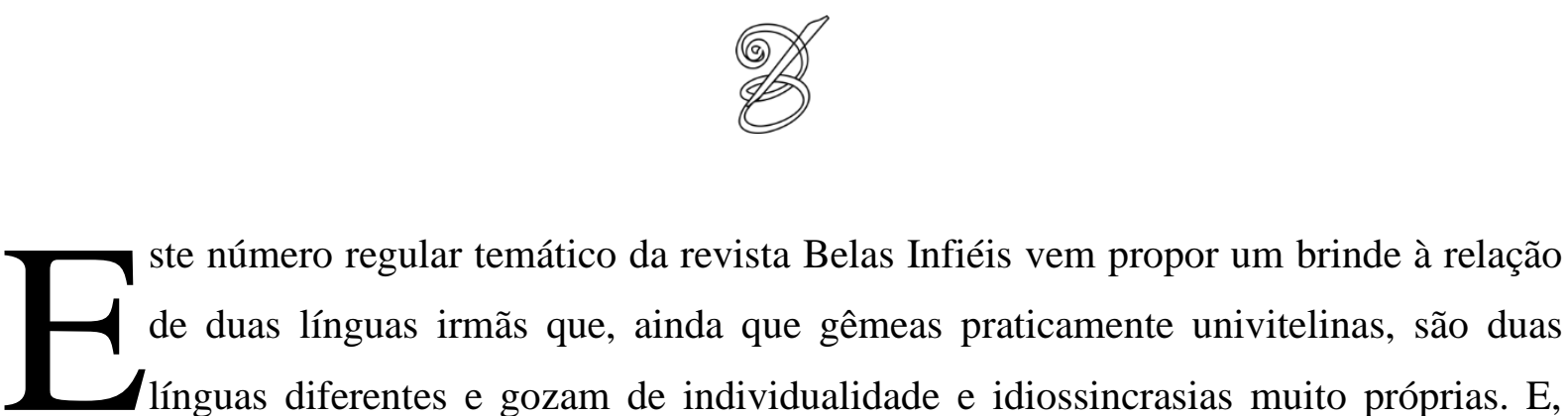

ste número regular temático da revista Belas Infiéis vem propor um brinde à relação de duas línguas irmãs que, ainda que gêmeas praticamente univitelinas, são duas línguas diferentes e gozam de individualidade e idiossincrasias muito próprias. E, para celebrar tamanho paradoxo, nada melhor que a tradução, que nessa relação, mais que dialógica e bilateral, não busca responder perguntas, mas sim fazê-las, provocá-las.

É inegável que a língua espanhola (ou castelhana) e o português compartilham "afinidades". Tal como irmãs, as semelhanças hereditárias das duas línguas não deixam de ser também uma espécie de carma, haja vista que não raras as vezes se confundem e podem confundir o tradutor, do novato ao experto. Talvez, por isso mesmo, tenham sido relegadas a padecer em um plano no qual a (in)compreensão reine diante de tanta (des)semelhança. Contudo, pese a que a igualdade seja a culpada de tantos males, a sociabilidade vocabular que lhes é marca latente também é a responsável por torná-las intrigantes, como o é tudo aquilo que contenha a substância genuína do complexo e rico espírito humano.

Retomando nossa metáfora dos gêmeos, reconhecer um indivíduo e tomá-lo por outro pode causar muitos problemas. Como também pode gerar desconforto, um irmão ver-se confundido pelo outro pelo simples fato de possuírem aparência quase que idêntica e terem suas personalidades e comportamentos, muitas vezes bem diferentes, ignorados e levados a um patamar de segunda categoria. Essa é a complexa relação de tradução entre os gêmeos espanhol<->português.

Como um dos eventos em comemoração aos 10 anos da implementação do curso de Tradução Espanhol da Universidade de Brasília, este número coaduna esforços no sentido de poner de relieve diversas nuances existentes na relação de tradução, ora alabada ora criticada entre espanhol $<>$ português. Para tanto, contou com a colaboração de acadêmicos dedicados ao estudo do par linguístico no Brasil e fora dele.

$\mathrm{O}$ artigo que abre este número temático, A noção de problema nos Estudos da Tradução: um novo olhar teórico com exemplos do par linguístico espanhol-português, escrito por Marina Leivas Waquil, da Universidade Federal do Rio Grande do Sul, traz a 
experiência de se traduzir ao português uma das obras mais citadas no campo disciplinar dos Estudos da Tradução, portanto, referência para pesquisadores em todo o mundo: Traducción y Traductología de Hurtado Albir. No processo de tradução, limitado ao $1^{\circ}$ capítulo da obra, a autora reflete sobre o conceito de problema, partindo de um viés filosófico até chegar ao conceito dentro dos Estudos da Tradução. Com o trabalho, foi possível quantificar e verificar problemas cuja frequência foi expressiva com relação à tradução envolvendo o par lingüístico espanhol-português.

Luis Carlos Ramos Nogueira, da Universidade de Brasília, nos presenteia com o artigo Vulgarização e destruição do falar andaluz na tradução literária. Tendo por base o conceito de tendências deformadoras de Berman, o autor propõe uma reflexão sobre o "apagamento das superposições de línguas e a destruição das redes linguísticas vernáculas”. Para tanto, desenvolve um estudo contrastivo de duas traduções, para o português do Brasil e de Portugal, de um excerto de La sombra del viento, de Luiz Carlos Zafón. Além de detectar uma séria de peculiaridades nos procedimentos utilizados para a tradução tais como: omissão, transformação, homogeneização, entre outros. O artigo mostra o paradoxo existente na atuação de ambos os tradutores, na qual os procedimentos adotados se encaixam dentro do conceito de tendências deformadoras proposto por Berman.

Também no campo literário, Rômulo Monte Alto, da Universidade Federal de Minas Gerais, discute em seu trabalho, José María Arguedas y João Guimarães Rosa frente a los abismos de la traducción, os abismos existentes, por um lado, na tradução de literatura brasileira para o español e, por outro, na tradução de literatura andina para o português. Um dos problemas de tradução colocado em destaque no trabalho diz respeito ao fato de tanto Guimarães Rosa como Arguedas possuírem um estilo que privilegia a oralidade, característica cujos tradutores buscam recuperar na língua-alvo. A análise impressa sobre as estratégias utilizadas pelos tradutores nos brinda com uma reflexão sobre o posicionamento desses tradutores com a relação original e cópia, além da fidelidade e originalidade dos textos fonte.

Em Implicações da globalização e da padronização linguística nos padrões de legendagem e o dialeto visual como estratégia para legendar a variação lingüística, Helena Santiago Vigata e Patrícia Tavares da Mata, da Universidade de Brasília, traz à tona um tema espinhoso, complexo e necessário: a questão da neutralização linguística da língua espanhola. Tendo a legendagem como exemplo prático da influência da referida padronização linguística, a autora nos oferece um panorâmico histórico do processo de globalização e o papel das políticas linguísticas no que se refere à implementação do chamado espanhol neutro. Dentre 
as consequências dessa neutralização, está o apagamento de marcas da oralidade e inclusive de traços da personalidade de personagens, tornando, segundo a autora, asséptica a linguagem empregada. Por fim, algumas possibilidades criativas do dialeto visual são exploradas enquanto estratégia para legendar a variação lingüística.

Ainda dentro do tema relacionado às diferentes formas de discurso, Ariel Novodvorski e Hellen Betin Miranda, da Universidade Federal de Uberlândia, apresentam em seu artigo Uma análise contrastiva dos bergoglismos em corpus de discursos do Papa Francisco, reflexões sobre os bergoglismos - fala peculiar do Papa Francisco - buscando analisar marcas de Avaliatividade nos discursos oficiais do Pontífice na língua espanhola e em suas traduções para o português. Lançando mão das ferramentas da Linguística de Corpus como metodologia, além da Teoria da Avaliatividade como suporte para o estudo, os autores analisam as construções neológicas do discurso papal e sua tradução ao português. A compilação do corpus paralelo no citado par linguístico e a metodologia utilizada podem ser replicadas em outros estudos, conforme sugerem os autores e abre janelas para novas possibilidades de estudos tanto no campo do neologismo como no campo da análise de discurso entre os idiomas espanhol-português.

No campo do discurso jurídico, Andrea Cristiane Kahmann e Daniel Alves, da Universidade Federal da Paraíba, discutem o uso do termo "verossimilar" habeas corpus em português e espanhol. No artigo intitulado Habeas corpus: reflexões teóricas e estratégias para a tradução (espanhol - português) do termo jurídico, os autores da Universidade Federal da Paraíba trazem à tona, além da limitação dos dicionários no que se refere à restrição de possibilidades de usos do termo, a necessidade de se conhecer a diversidade de usos existentes nos diferentes sistemas jurídicos dos países de língua espanhola. Partindo da premissa que o termo se insere no conceito de item cultural específico, coloca-se em pauta a relação do termo jurídico, como mantenedor de liberdades, com seus contextos específicos de aplicação dentro dos discursos jurídicos de cada país. Ademais, sugerem-se "seis possíveis estratégias para a manipulação" do termo em processos de tradução no par linguístico espanhol-português.

A relação de tradução impressa na banda sonora dos filmes de Almodóvar na modalidade legendagem é o tema central do artigo Cinema, Música e Tradução: Pedro Almodóvar legendando em Portugal de Maria Dolores Lerma Sanchis, da Universidade do Minho, Portugal. Partindo dos conceitos de normas preliminares e normas operacionais proposto por Toury (1995), o estudo buscou constatar a existência ou não de normas na 
tradução das músicas dos oito últimas longas metragens desde 1999 a 2016. Como resultado, a autora do estudo conclui que não há um padrão de tradução das músicas, ainda que haja uma intercompreensão e uma proximidade linguística e territorial que pudesse influenciar a elaboração das legendas. Igualmente, o estudo constatou que somente um terço das músicas é legendado, não existindo uma homogeneidade nas propostas de tradução analisadas e impactando nas nuances apresentadas nas canções.

Afinado ao tema da (in)existência de fronteiras entre os dois idiomas, o artigo Fronteiras de tradução em contos de José Monegal fecha a seção de artigos deste número especial. Carlos García Rizzon, da Universidade Federal do Pampa, nos oferece comentários sobre a tradução para a língua portuguesa de marcas fronteiriças existentes tanto nos "temas como na forma do texto" do conto Arquétipo, de José Monegal. Como parte de um projeto de pesquisa intitulado Fronteiras da tradução literária, na experiência relatada com estudantes bolsistas, o autor se permite corromper a escrita padrão, oferecendo ao leitor aproximações e distanciamentos entre os dois idiomas, além de recriar as características das falas dos personagens, recriando, consequentemente, suas personalidades.

Além dos artigos ora apresentados, este número ainda conta com três traduções comentadas. Em Uma tradução de O cágado, poema de Guimarães Rosa, para o espanhol, Raimundo Expedito dos Santos Sousa (Faculdade do Centro Educacional Mineiro) e Hugo Dominguez Silva (Universita Degli Studi di Napoli L'Orientale, Itália) se debruçam sobre a tradução do poema do autor brasileiro para a língua espanhola "cuja primazia repousa no elemento rítmico".

Em direção inversa, ou seja, do espanhol para o português, Maria Liz Benítez Almeida (Universidade Federal do Rio Grande do Sul) propõe uma Tradução comentada do conto Cinta grabada do escritor paraguaio Mario Halley Mora. No trabalho, a autora apresenta questões relacionadas às especificidades do texto fonte, escrito em espanhol e guarani, além das características dos personagens impressas nas suas formas peculiares de falar e sua recriação em português.

Encerrando a seção de traduções comentadas, Luciana Ferrari Montemezzo (Universidade Federal de Santa Maria) apresenta A produção literária contemporânea na Espanha: Caleidoscópio de sensações, de Elvira Cámara Aguilera - tradução anotada e comentada. No trabalho, cujo objetivo principal é apresentar ao público brasileiro a autora espanhola, Luciana tece comentários sobre o processo de tradução da obra, além de reivindicar um lugar de destaque para a tradução literária. 
Fechando nosso número especial com chave de outro, trazemos uma entrevista com a professora e pesquisadora Adriana Pagano. Na entrevista, a professora do Laboratório Experimental de Tradução (LETRA) nos presenteia com reflexões sobre o papel dos idiomas no processo tradutório, a relação de parentesco entre o castelhano e o português e estimula a formação de novos pesquisadores em tempos tão difíceis para as ciências humanas. Nesse âmbito, discorre sobre o papel das novas tecnologias e afirma: "no me canso de decir, el siglo 21 es el siglo de las humanidades".

Sem a pretensão de sermos conclusivos com relação aos estudos envolvendo o par linguístico espanhol< > português, uma vez que uma infinidade de outros pesquisadores e outras pesquisadoras que não estão neste número (mas poderiam estar), também representam aqueles que se interessam pelo estudo do tema; celebramos todos aqueles e todas aquelas que se dedicam a traduzir o próprio irmão, algumas vezes com e outras sem sucesso. Esperamos que o leitor e a leitora da área da tradução se deliciem com os trabalhos e que os leitores e leitoras, que não são da área de tradução, sintam-se estimulados(as) a conhecer um pouco mais dessa tão complexa, intrigante e apaixonante área do tão necessário mundo das ciências humanas.

Boa leitura!

Gleiton Malta

(UnB) 